\title{
On Debugging of Secondary Equipment of Digital Substation based on IEC61850-9-2
}

\author{
Zhang Xueqiang ${ }^{1}$, Cheng Zhiyuan ${ }^{2}$ \\ ${ }^{1}$ Maoming Power Supply Bureau of Guangdong Power Grid Corporation, located in Maoming, \\ Guangdong, 525000, China \\ ${ }^{2}$ Guangzhou PtSwitch Electric Power Science and Technology Co., Ltd, located in Guangzhou, \\ Guangdong, 510600, China \\ Xuexi123@163.com
}

Keywords: IEC61850-9-2 standard, digital substation, secondary equipment, commissioning.

\begin{abstract}
. since 1990s, the substation has entered the digital age along with rapid development of information control technology, power grid technology, computer technology and measuring technology, and a great breakthrough has been made in aspects of function improvement, cost reduction, reliability enhancement and information share. The secondary equipment of the digital substation includes a misoperation-preventive locking device, a relay protection device, a fault recording device, an online status monitoring device and a telemechanical device. As the devices are connected mutually in a high-speed network communication manner, a high standard is required for the debugging work. However, the domestic research is still feeling its way, and thus it is particularly important for us to draw lessons from the experiences on debugging the secondary equipment of the digital substation and develop a standardized debugging procedure.
\end{abstract}

\section{STRUCTURE OF DIGITAL SUBSTATION BASED ON IEC61850-9-2 STANDARD}

The digital substation based on IEC61850-9-2 refers to a substation, which realizes unimpeded information transmission inside and outside the substation through standardization of digitized information by taking the primary and secondary equipment of the substation as the to-be-digitalized objects and the high-speed network communication platform as the base, and realizes automatic functions like control protection, measurement monitoring and information management by virtue of the network data, within constraints of the IEC61850-9-2 standard. The structure of the digital substation based on IEC61850-9-2 is shown in Fig.1.

The station level consists of a telecommunication interface, an operator workbench, a computer and so on. The station level mainly performs online configuration and online maintenance to the devices in the bay level and the process level, transfers the commands from the control center or the dispatching center to the bay level and the process level for execution, and transfers data information to the control or dispatching center according to relevant regulations in the IEC61850-9-2 Standard.

The bay level consists of protection, control or monitoring units of all bays, and mainly protects the primary device, collects real-time data information from the bay level and transfers to the station level, and controls the connecting communication functions by priority.

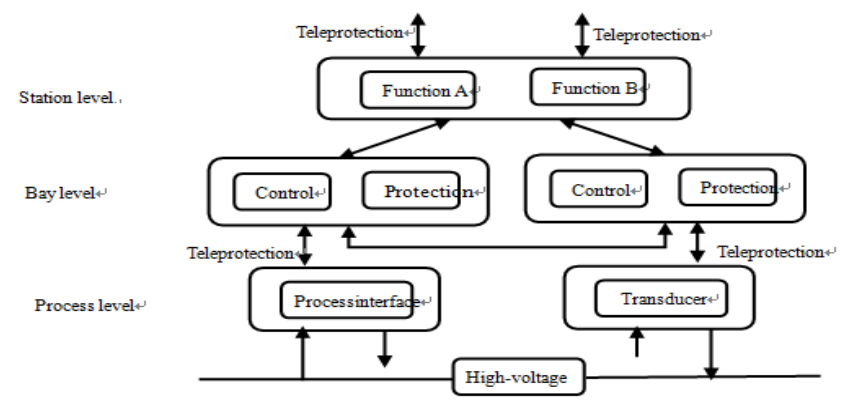

Fig. 1 Structure of Digital Substation based on IEC61850-9-2 Standard 
The process level is the key point for combination of the primary device and the secondary device in the digital substation, mainly tests real-time electric parameters during power operation, monitors and counts state parameters of the operating device, and executes and drives operation control including on/off control for both the disconnector and the electric reactor.

\section{COMMISSIONING PROCEDURE FOR SECONDARY EQUIPMENT IN DIGITAL SUBSTATION BASED ON IEC61850-9-2}

The debugging procedure of the digital substation is different from that of the normal substation, and targets at diverse and complex objects, therefore the overall debugging process should be carried out for realizing zero defect and efficient operation of the digital substation. In my view, the debugging procedure of the digital substation based on the IEC61850-9-2 standard comprises the following steps:

(1)leave-factory check and acceptance. The leave-factory check and acceptance lays emphasis on check and acceptance of the manufacturing technique and procedure for the secondary equipment, so that the equipment can satisfy requirements of relevant rules, standards and order contracts.

(2)function debugging for field devices. The function debugging for the field devices is to test the function and performance of the secondary equipment by adopting a tester according to relevant testing scheme, after assembling and wiring of the secondary system equipment.

(3) function debugging for field systems. The function debugging for the field systems refers to system integration and test, global-set drive, telecontrol communication system debugging, station level monitoring system debugging and others after function debugging of all field devices.

(4)performance debugging of field systems. The field system performance debugging lays emphasis on testing the performance indexes of the secondary systems, for example, testing the transmission time of the guidance command for execution, testing the network load rate and so on.

(5)startup debugging. Only after the integrated drive is qualified and accepted by the relevant department, the startup debugging can be performed. The startup debugging lays emphasis on check of stable operation of the secondary systems by testing during hot-line work. During startup debugging, for lack of connection by conventional secondary cables with current and voltage, we check the phasors mainly by virtue of measuring values from the protective device.

\section{KEY POINT FOR DEBUGGING SECONDARY EQUIPMENT OF DIGITAL SUBSTATION BASED ON IEC61850-9-2}

From the above, we can see that the debugging of the secondary equipment of the digital substation covers a wide range, so this article will focus on the links liable to faults

Leave-factory check and acceptance for secondary equipment. The digital substations in domestic have been placed in service gradually, and the IEC61850-9-2 standard has been widely applied to the automatic protection devices and the monitoring system networks. However, it is noteworthy that the manufacturers of the secondary equipment comprehend the IEC61850-9-2 standard in different ways, which results in inconsistent definition of the transmission frames of the secondary equipment produced by different manufacturers. For this reason, the field debugging and maintenance personnel should check the equipment from different manufacturers for acceptance before the equipment leaves the factories, and ensure that the equipment can work normally when arriving at the field.

The specific items for leave-factory check and acceptance of the secondary equipment is shown in Table 1. 
Table 1 Specific Items for Leave-factory Check and Acceptance of Secondary Equipment of Digital Substation

\begin{tabular}{|c|c|}
\hline Items for acceptance & Contents \\
\hline Equipment check & $\begin{array}{l}\text { Check whether the appearances, the nameplates, the interior structures, the terminal boards } \\
\text { and the interior wires of all cabinets conform to the requirements or not. }\end{array}$ \\
\hline File check & $\begin{array}{l}\text { Check whether the technical data, the delivery test reports and the leave-factory certificates } \\
\text { along with the equipment are complete or not. }\end{array}$ \\
\hline IEC61850 test & Perform the model test, the association test, the GOOSE test, the interoperability test, etc. \\
\hline $\begin{array}{l}\text { Acceptance test for } \\
\text { monitoring systems }\end{array}$ & $\begin{array}{l}\text { Carry out the acceptance tests for the station level, the bay level and the process level } \\
\text { respectively }\end{array}$ \\
\hline $\begin{array}{l}\text { Acceptance test for protective } \\
\text { device }\end{array}$ & $\begin{array}{l}\text { Check the configuration files, test the sampling precision, verify the protection logic and } \\
\text { setting values, etc. }\end{array}$ \\
\hline $\begin{array}{l}\text { Performance test for network } \\
\text { equipment }\end{array}$ & $\begin{array}{l}\text { Test the load rate of the network, the handling capacity of the exchangers, the packet loss rate } \\
\text { of the exchangers, the receiving/sending power, etc. }\end{array}$ \\
\hline Accuracy test for time tick & Check whether the accuracy of the device clock conforms to the requirement or not \\
\hline $\begin{array}{c}\text { Time test for global-set drive } \\
\text { protection and global-set } \\
\text { operation }\end{array}$ & Link the whole system for operation, check activity of relevant outlets and signals \\
\hline
\end{tabular}

Function debugging for field devices. The function debugging for the field devices aims at verifying all functions of the devices. As the devices are greatly different in functions, the debugging items for different devices are different. Refer to Table 2 for details.

Table 2 Items of Function Debugging for Field Devices in Digital Substation

\begin{tabular}{cl}
\hline Devices & Debugging items \\
Eurrent/voltage transformer & $\begin{array}{l}\text { Test the sampling precision and the sampling synchronism of the sampler, and perform the } \\
\text { optical fiber link interruption \& recovery test }\end{array}$ \\
Merging unit & $\begin{array}{l}\text { Check the appearance, the working power supply, the software, the communication function, } \\
\text { the alarm function, the switching on function and the voltage switchover function }\end{array}$ \\
Intelligent terminal & $\begin{array}{l}\text { Check the appearance, the working power supply, the software, the communication function, } \\
\text { the alarm function, the switching-on function, the remote signaling and control function }\end{array}$ \\
Protective device and & $\begin{array}{l}\text { Check the appearance, the working power supply, the software, the communication function, } \\
\text { the alarm function, the sampling function and the background monitoring message and signal, } \\
\text { and verify the logic and setting values of the protective device or the monitoring and control } \\
\text { device }\end{array}$ \\
Intelligent exchanger & $\begin{array}{l}\text { Check the appearance, the working power supply, the administrator settings, the Ethernet } \\
\text { ports, the communication interfaces, the alarm function, the spanning tree protocols, the } \\
\text { VLAN settings and the service category }\end{array}$ \\
Network state monitoring & $\begin{array}{l}\text { Check the appearance, the working power supply, the project configuration and the } \\
\text { communication function, and debug the network message analyzer and the network } \\
\text { communication real-time status monitoring function }\end{array}$
\end{tabular}

Network communication and performance test.

(1)Network communication test. The network communication test includes the network delay test, the communication interface check and the communication function check, wherein the communication function check is elaborated hereinafter. For the purpose that the whole secondary system can still run normally in case of a communication network failure of the secondary system of the digital substation, the network communication function test is required. By taking the communication interruption test for the MU and the collector as an example, the specific testing method is shown as follows: when the connecting optical fiber for the MU and the collector is pulled out, the equipment gives a prompt of "CT disconnection" or "PT disconnection" and the warning light goes on, and meanwhile, the background receives the warning signal of "CT disconnection" or "PT disconnection"; and then, when the connecting optical fiber of the MU and the collector is inserted, the signal is reset. 
(2)Network performance test. The network performance of the secondary system of the digital substation relates to several crucial indexes including the handling capacity, the time delay and the packet loss rate, wherein the handling capacity refers to the limit quantity of the packets forwarded in one second on the premise of no packet loss and used for measuring the data packet forwarding capacity of the exchanger; the time delay refers to the time interval from the time point of input of the last bit of the input frame to the time point of output of the first bit of the output frame, and is usually takes the average value of the test values obtained through repeated tests; and finally, the packet loss rate mainly refers to the proportion of lost packets in the packets to be forwarded by the exchanger under different load conditions. The different load conditions normally refer to the handling capacity test and the line rate (the highest transmission rate of the packets on the line) test, and the step value is generally set to be $10 \%$ of the line rate.

\section{SUMMARY}

As an important link for ensuring successful operation of the digital substation, the secondary equipment test covers lots of objects and relates to different debugging methods. Thus, the technicians are required to draw lessons from the experiences unceasingly, so as to develop a standardized debugging procedure for the secondary equipment of the digital substation, complete the debugging methods for the secondary equipment and correct the debugging methods in consideration of the problems occurring during the testing process. I firmly believe that by virtue of scientific standardized debugging, the major problems of the equipment can be solved before the equipment leaves the factory and the smooth operation of the digital substation can be guaranteed.

\section{REFERENCES}

[1] Jin Fei, On Joint Debugging of Secondary Equipment of Intelligent Substation before Delivery [J], Silicon Valley, 2013 (16) 121-126.

[2] Xu Ying \& Li Chaoxun, Debugging and Overhauling of Secondary Equipment of Intelligent Substation [J], Science and Technology Information, 2012 (35) 13-18.

[3] Li Yan \& Zhao Lijun, On Intelligent Substation Secondary Debugging Method, Northeast Electric Power Technology, 2012, 7 (12) 111-112.

[4] Gao Xiang \& Zhang Peichao, Main Features and Key Technologies of Digital Substation [J], Power System Technology, 2006, 30 (23)11-12. 